\title{
microRNA network analysis identifies miR-29 cluster as key regulator of LAMA2 in ependymoma
}

\author{
Anbarasu Lourdusamy*, Ruman Rahman, Stuart Smith and Richard Grundy
}

Keywords: microRNA, Ependymoma, Regulatory network, Microarray

Ependymomas (EPN) are enigmatic tumors which continue to present significant management challenges to clinicians as evidenced by the failure to cure up to $40 \%$ of cases [1]. Recent genomic and epigenomic studies have identified alterations in DNA copy number, gene expression $[2,3]$, and methylation [4] and showed that EPN is a heterogeneous disease and consists of distinct molecular subtypes. However, the involvement of the microRNAs (miRNA) and their influence over mRNA translation into proteins, in EPN and their contribution to the complexity of the disease are still poorly understood.

To identify miRNA - mRNA regulatory network, we systematically evaluated miRNA - mRNA associations using expression profiles of tumors from 64 EPN patients (mean age of 13.3 years, Additional file 1: Table S1 for more details). For each miRNA-mRNA pair, we measured the association between miRNA and mRNA using a Spearman rank correlation and filtered with sequence-based predicted miRNA-target interactions of miRanda and TargetScan databases Additional File 3: Materials and methods [5,6]. We selected miRNA-mRNA pairs with strong negative correlation (FDR $<0.005,78,934$ pairs) and evidence for target interaction as predicted by miRanda (score $<-0.5$ ), TargetScan (context score $<-0.2$ ) and evolutionary conservation (miRanda conservation score $>0.5$ ). We used these thresholds to obtain a high-confidence list of candidate miRNAtarget interactions. The combination of the correlation and target prediction filters yielded 390 miRNA-mRNA pairs, significantly more than was expected by chance $(P=5.95 \times$ $10^{-08}$, two-tailed binomial test, $x=390, n=78,934, p=$ $3.71 \times 10^{-03}=28,309$ predicted targets $/ 7,623,897$ total pairs). These 390 putative target interactions from EPN consisted of 107 evolutionarily conserved miRNAs and 305 target mRNAs (Additional file 1: Table S2). Remarkably, these miRNAs are significantly enriched for oncomiRs/

\footnotetext{
* Correspondence: anbarasu.lourdusamy@nottingham.ac.uk

Children's Brain Tumour Research Centre, School of Medicine, Queen's Medical Centre, University of Nottingham, Nottingham NG7 2UH, UK
}

tumor suppressor miRNAs (2.01 fold enrichment; $\mathrm{P}=$ $9.41 \times 10^{-03}$, Fisher's exact test. Additional file 2: Figure S1). They included let-7c, miR-125b, miR-29a/b, miR-15 family - miR-15a, miR-16, and miR-196 (tumor suppressors miRNA), miR-18a/b, miR-19a/b, and miR-17 family - miR106a/b, miR-17, miR-20a/b, and miR-93 (onco miRNA). Growing evidences suggest that miR-17 miRNAs are involved in cell proliferation, development, and stem cell differentiation [7]. In addition, members of miR-17 directly target TGFBR2, attenuate TGF- $\beta$ signaling that regulates multitude of cellular processes, and is particularly relevant not only during development, but also in cancer initiation and progression $[7,8]$. Targets genes regulated by miRNAs are enriched for biological processes or pathways such as multicellular organismal development (GO:0007275; FDR $=3.31 \times 10^{-04}$ ), neuron differentiation (GO:0030182; FDR $=3.85 \times 10^{-04}$ ), regulation of cell adhesion (GO:0030155; $\left.\mathrm{FDR}=3.75 \times 10^{-03}\right)$, MAPK signalling pathways (hsa04010; $F D R=2.67 \times 10^{-03}$ ), pathways in cancer (hsa05200; $\quad F D R=3.60 \times 10^{-03}$ ), extracellular matrix $(\mathrm{ECM})$ receptor interaction (hsa04512; FDR $=1.22 \times 10$ ${ }^{-02}$ ), and Integrin, EGF receptor, Wnt, and Neurotrophin signaling pathways (Additional file 1: Table S3 ). Enrichment of known cancer-related processes and pathways among miRNAs and target genes suggest that inferred miRNA-target relationships have functional roles in EPN.

The inferred putative target interactions from EPN formed a network with 11 highly interconnected subnetworks (Additional file 2: Figure S2). At least 50 of the 390 EPN target interactions (comprising 25 miRNAs and 35 mRNAs) have strong evidence of recurrence in multiple cancer types (recurrence score $<-3.0$ and FDR $<$ 0.05) on the basis of The Cancer Genome Atlas (TCGA) miRNA-target interactions analysis across 10 cancer types (Figure 1, Additional file 1: Table S2) [9]. EPN interactions with high recurrence score include pairs such as miR18a:CREBL2 (REC score $=-10.56 ; \quad F D R=1.81 \times 10^{-07}$ ), miR-106b:TGFBR2 $\left(\mathrm{REC}=-9.07 ; \mathrm{FDR}=2.52 \times 10^{-06}\right)$, and the interactions between the miR-29 family and NREP 


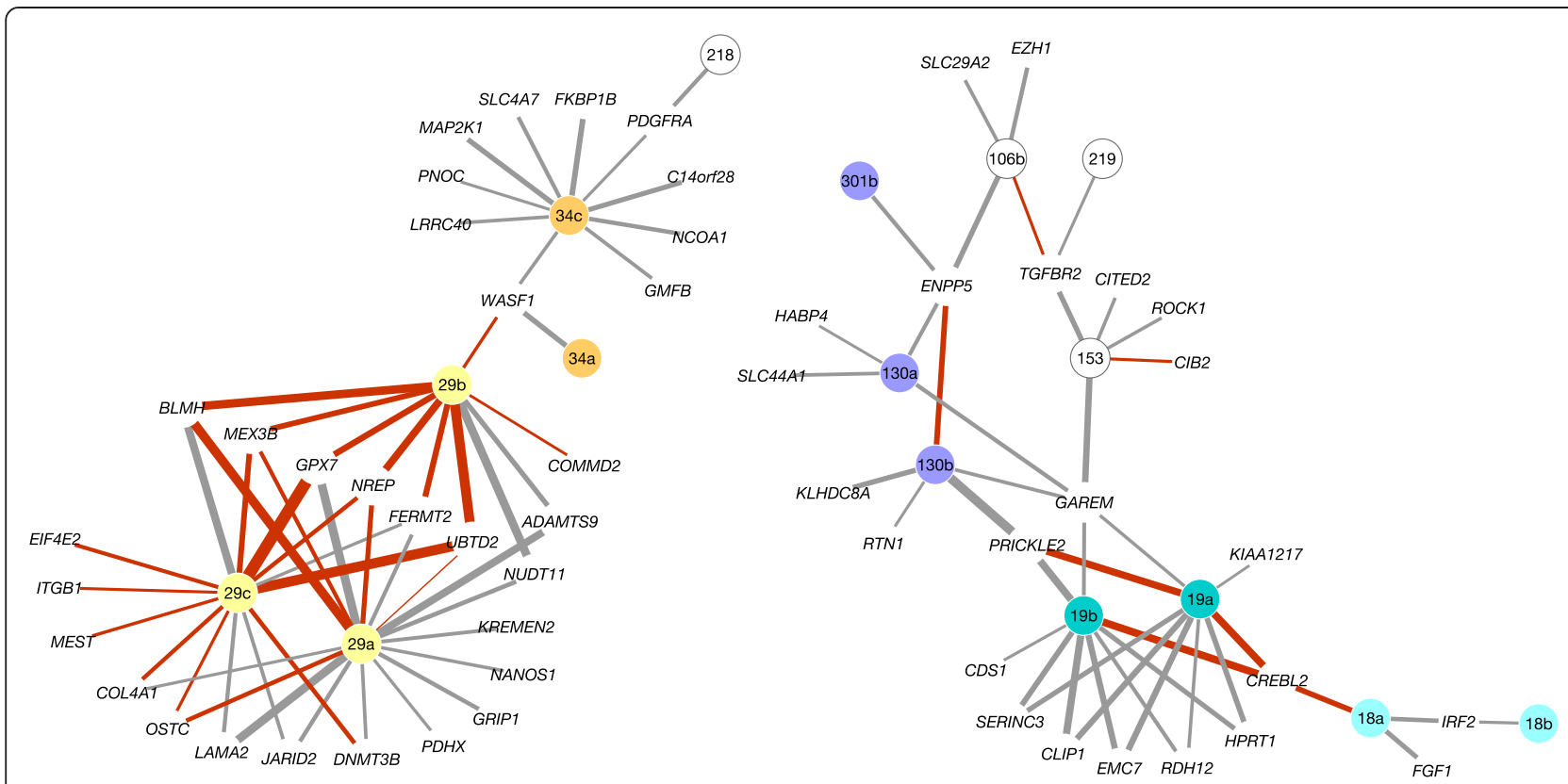

Figure 1 Ependymoma network of miRNA-mRNA target interactions. Two highly connected sub-networks from the inferred network of ependymoma comprising 390 putative target interactions between 107 miRNAs and 305 target mRNAs. Edge width represents strength of Spearman rank correlation for a given miRNA-mRNA pair, red edge colour represents evidence of recurrence in multiple cancer types, and miRNAs from the same family are color coded while a single miRNA is shown in white.

$\left(\mathrm{REC}=-19.74 ; \mathrm{FDR}=7.05 \times 10^{-15}\right)$, UBTD2 $(\mathrm{REC}=-9.97$ $\left.\mathrm{FDR}=4.99 \times 10^{-07}\right)$, and $M E X 3 B(\mathrm{REC}=-5.86 ; \mathrm{FDR}=$ $6.64 \times 10^{-04}$ ) that physically interacts with the AGO1 gene, encoding a member of the Argonaute family of proteins which play a role in RNA interference by miRNAs via the RISC complex. The network also showed several novel EPN-specific interactions with genes that are involved in axon guidance (miR-29a:LAMA2, miR-29c:LAMA2), histone H3-K27 methylation (miR-106B:EZH1), chromatin modification (miR-29c:JARID2), and methylationdependent chromatin silencing (miR-29a:DNMT3B).

Next, we asked whether the network represented by these putative target interactions captures the salient transcriptomic features of EPN subgroups, particularly from posterior fossa (PF). In line with earlier studies, a consensus clustering analysis of mRNA expression data among 64 EPN cases led to the identification of three transcriptional subtypes: largely supratentorial (ST, $37.5 \%)$, PF with spinal (SP) and ST (PF + SP + ST, 29.7\%), and largely PF (PF, 32.8\%) (Additional file 2: Figure S3). The group largely associated with PF (named as PFA) comprised predominantly of children with mean age of 3.5 years (range from $0.4-9.2$ years), whereas the PF clustered with SP and ST (named as PFB) consisted of adults with a mean age of 24.5 years (range from 8 45 years) (Additional file 2: Figure S4). The differential expression analysis between the two PF subgroups detected a total of 46 mRNA targets as significant $(F D R<0.05)$, and 27 of these were also differentially expressed in an independent dataset $\left(\mathrm{P}=6.20 \times 10^{-05}\right.$, Fisher's exact test) of 37 PF EPN from the previously published study (Additional file 1: Table S4). Remarkably, the direction of expression differences between two PF subgroups was same in both cohorts for all of the 27 overlapping differentially expressed genes (Additional file 2: Figure S4). Fifteen overlapping mRNA target genes showed high levels of expression in the PFA subgroup, of which four (ACSL6, ATP1B2, CAMK2B, and S1PR1) were regulated by miR-24, four (ADAMTS9, BLMH, $L A M A 2$, and NUDT11) were regulated by the miR-29 family, three (MMD, PKIA, and STK39) were regulated by miR-27b, and PDGFRA was regulated by miR-34c and miR-218. Interestingly, $L A M A 2$ has previously been identified as a candidate maker gene for PFA subgroup and associated with poor prognosis [3,10,11]. In addition to a strong miR29a:LAMA2 association $(r=-0.62$; FDR $\left.=1.18 \times 10^{-05}\right)$, we also observed an inverse correlation between LAMA2 and miR29c $(r=-0.49$; FDR $=$ $1.61 \times 10^{-03}$ ) in $\mathrm{EPN}$, but not in other cancer types (Figure 2). The two miR-29 family miRNAs are encoded at two different genomic loci, yet they showed anti-correlation with $L A M A 2$ in EPN, suggesting EPNspecific strong co-regulation of the miR-29 loci. Taken together, these results suggest that downregulation of 


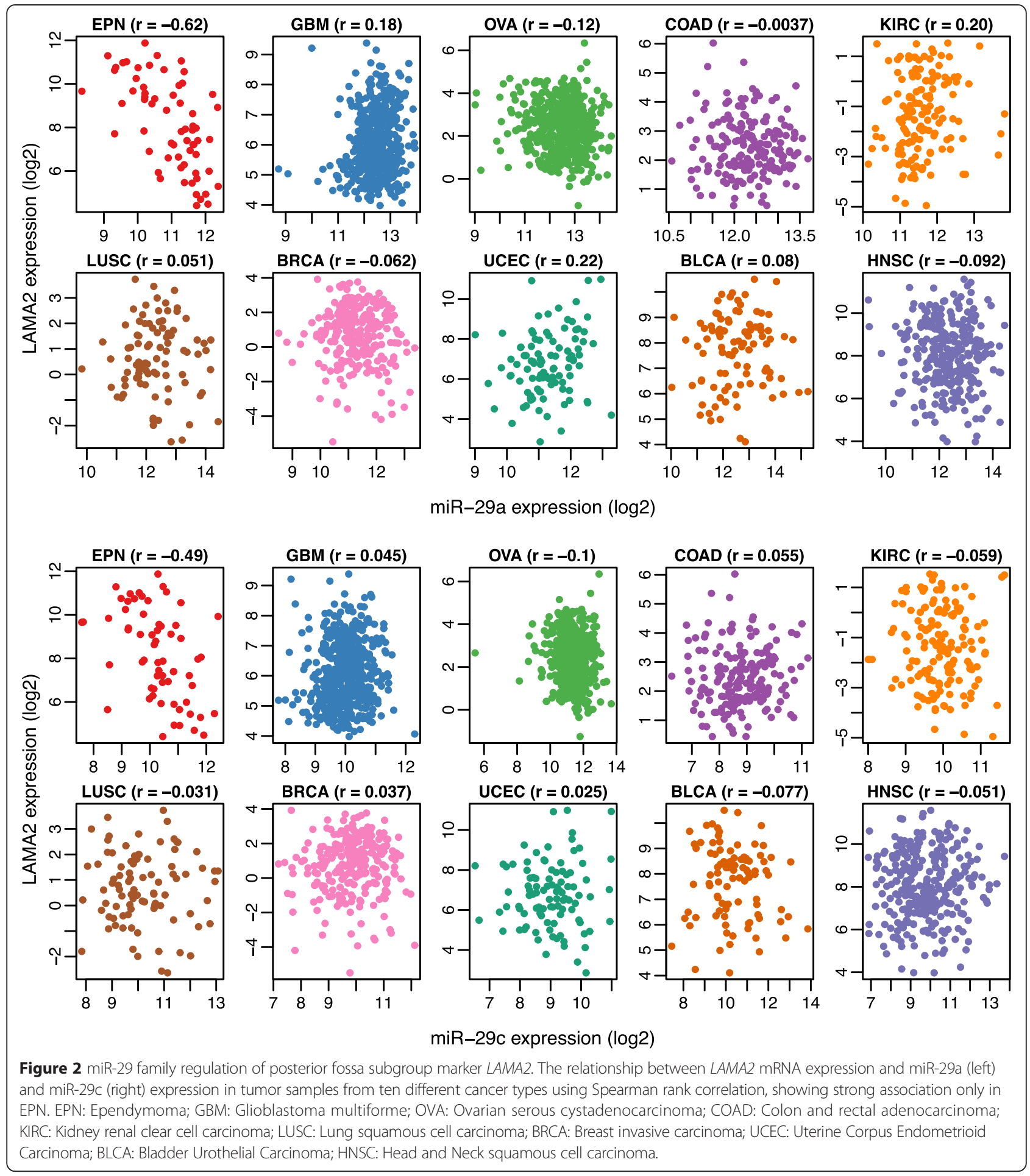

miR-29 family expression is a potent mechanism by which $L A M A 2$ expression is altered in PF ependymoma.

In summary, we identified miR-29a/c as novel regulators of $L A M A 2$ in ependymoma based on miRNAmRNA covariation and sequence-based target predictions.
The decreased expression of miR-29a/c and elevated $L A M A 2$ expression are therefore defining features of PF ependymoma post-transcriptional regulation, indicating a key mechanism for molecular pathogenesis. Apart from changes in miRNA expression, other 
mechanisms (genetic or epigenetic) can contribute to $L A M A 2$ expression in PF ependymoma, which now mandates further investigation.

\section{Additional files}

Additional file 1: Table S1. Characteristics of ependymoma patients used in the current study. Table S2. Putative miRNA - target interactions from Ependymoma expression data. Table S3. Enrichment of biological processes and pathways. Table S4. Differential expression of miRNA target genes in PF subgroups.

Additional file 2: Figure S1. miRNAs in the miRNA-target network are enriched for oncomir and tumor suppressor miRNAs. Figure S2. Inferred miRNA-target network of 390 putative target interactions is clustered into 11 highly interconnected sub networks. Figure S3. Performance of consensus clustering showing optimum partitioning of three ependymoma (EPN) subtypes. Figure S4. Characteristics of two PF subgroups (difference in Age, left and consistent difference in gene expression).

Additional file 3: Materials and methods.

\section{Abbreviations}

EPN: Ependymoma; miRNA: micro RNA; ECM: Extra cellular matrix; TCGA: The Cancer Genome Atlas; PF: Posterior fossa; ST: Supratentorial; SP: Spinal; PFA: Posterior fossa subgroup A; PFB: Posterior fossa subgroup B.

\section{Competing interests}

The authors declare that they have no competing interests.

\section{Authors' contributions}

AL conceived and designed the study, collected and analyzed the data, interpreted results, and drafted the manuscript. RR interpreted results and drafted the manuscript. SS interpreted results and drafted the manuscript. RG interpreted results, drafted the manuscript, and obtained funding. All authors read and approved the final manuscript.

\section{Acknowledgments}

This work was supported by the Air \& Ground Charity, Gentleman's Night Out Fund and the Children's Brain Tumour Research Centre (CBTRC).

Received: 23 April 2015 Accepted: 26 April 2015

Published online: 10 May 2015

\section{References}

1. Hasselblatt M (2009) Ependymal tumors. Recent Results Cancer Res 171:51-66

2. Johnson RA, Wright KD, Poppleton H, Mohankumar KM, Finkelstein D, Pounds SB, Rand V, Leary SE, White E, Eden C, Hogg T, Northcott P, Mack S, Neale G, Wang YD, Coyle B, Atkinson J, DeWire M, Kranenburg TA, Gillespie Y, Allen JC, Merchant T, Boop FA, Sanford RA, Gajjar A, Ellison DW, Taylor MD, Grundy RG, Gilbertson RJ (2010) Cross-species genomics matches driver mutations and cell compartments to model ependymoma. Nature 466(7306):632-636

3. Witt H, Mack SC, Ryzhova M, Bender S, Sill M, Isserlin R, Benner A, Hielscher T, Milde T, Remke M, Jones DT, Northcott PA, Garzia L, Bertrand KC, Wittmann A, Yao Y, Roberts SS, Massimi L, Van Meter T, Weiss WA, Gupta N, Grajkowska W, Lach B, Cho YJ, von Deimling A, Kulozik AE, Witt O, Bader GD, Hawkins CE, Tabori U et al (2011) Delineation of two clinically and molecularly distinct subgroups of posterior fossa ependymoma. Cancer Cell 20(2):143-157

4. Mack SC, Witt H, Piro RM, Gu L, Zuyderduyn S, Stutz AM, Wang X, Gallo M, Garzia L, Zayne K, Zhang X, Ramaswamy V, Jager N, Jones DT, Sill M, Pugh TJ, Ryzhova M, Wani KM, Shih DJ, Head R, Remke M, Bailey SD, Zichner T, Faria CC, Barszczyk M, Stark S, Seker-Cin H, Hutter S, Johann P, Bender S et al (2014) Epigenomic alterations define lethal CIMP-positive ependymomas of infancy. Nature 506(7489):445-450

5. Betel D, Koppal A, Agius P, Sander C, Leslie C (2010) Comprehensive modeling of microRNA targets predicts functional non-conserved and non-canonical sites. Genome biology 11(8):R90
6. Grimson A, Farh KK, Johnston WK, Garrett-Engele P, Lim LP, Bartel DP (2007) MicroRNA targeting specificity in mammals: determinants beyond seed pairing. Molecular cell 27(1):91-105

7. Mogilyansky E, Rigoutsos I (2013) The miR-17/92 cluster: a comprehensive update on its genomics, genetics, functions and increasingly important and numerous roles in health and disease. Cell death and differentiation 20(12):1603-1614

8. Dews M, Fox JL, Hultine S, Sundaram P, Wang W, Liu YY, Furth E, Enders GH, El-Deiry W, Schelter JM, Cleary MA, Thomas-Tikhonenko A (2010) The myc-miR$17 \sim 92$ axis blunts TGF\{beta\} signaling and production of multiple TGF $\{$ beta\}dependent antiangiogenic factors. Cancer research 70(20):8233-8246

9. Jacobsen A, Silber J, Harinath G, Huse JT, Schultz N, Sander C (2013) Analysis of microRNA-target interactions across diverse cancer types. Nature structural \& molecular biology 20(11):1325-1332

10. Hoffman LM, Donson AM, Nakachi I, Griesinger AM, Birks DK, Amani V, Hemenway MS, Liu AK, Wang M, Hankinson TC, Handler MH, Foreman NK (2014) Molecular sub-group-specific immunophenotypic changes are associated with outcome in recurrent posterior fossa ependymoma. Acta neuropathologica 127(5):731-745

11. Wani K, Armstrong TS, Vera-Bolanos E, Raghunathan A, Ellison D, Gilbertson R, Vaillant B, Goldman S, Packer RJ, Fouladi M, Pollack I, Mikkelsen T, Prados M, Omuro A, Soffietti R, Ledoux A, Wilson C, Long L, Gilbert MR, Aldape K, Collaborative Ependymoma Research N (2012) A prognostic gene expression signature in infratentorial ependymoma. Acta neuropathologica 123(5):727-738

\section{Submit your next manuscript to BioMed Central and take full advantage of:}

- Convenient online submission

- Thorough peer review

- No space constraints or color figure charges

- Immediate publication on acceptance

- Inclusion in PubMed, CAS, Scopus and Google Scholar

- Research which is freely available for redistribution

Submit your manuscript at www.biomedcentral.com/submit
C BioMed Central 